\title{
G

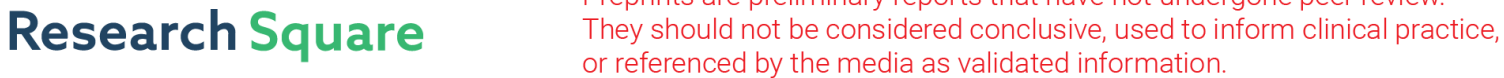 \\ Influence of Sex on Survival Rates of HPV Positive Oropharyngeal Cancers
}

\section{Sally H Preissner}

Charité - Universitätsmedizin Berlin, Corporate Member of Freie Universität Berlin, Humboldt-Universität zu Berlin, Berlin Institute of Health

\section{Susanne Nahles}

Charité - Universitätsmedizin Berlin, Corporate Member of Freie Universität Berlin, Humboldt-Universität zu Berlin, Berlin Institute of Health

\section{Saskia Preissner}

Charité - Universitätsmedizin Berlin, Corporate Member of Freie Universität Berlin, Humboldt-Universität zu Berlin, Berlin Institute of Health

\section{Max Heiland}

Charité - Universitätsmedizin Berlin, Corporate Member of Freie Universität Berlin, Humboldt-Universität zu Berlin, Berlin Institute of Health

\section{Benedicta Beck-Broichsitter}

Charité - Universitätsmedizin Berlin, Corporate Member of Freie Universität Berlin, Humboldt-Universität zu Berlin, Berlin Institute of Health

\section{Steffen Koerdt ( $\square$ steffen.koerdt@charite.de )}

Charité - Universitätsmedizin Berlin, Corporate Member of Freie Universität Berlin, Humboldt-Universität zu Berlin, Berlin Institute of Health

\section{Research Article}

Keywords: Oral Cancer, HPV, Oropharyngeal Cancer, Sex

Posted Date: September 7th, 2021

DOl: https://doi.org/10.21203/rs.3.rs-744802/v1

License: (c) (1) This work is licensed under a Creative Commons Attribution 4.0 International License. Read Full License 


\section{Abstract}

The role of human papillomavirus (HPV) status for the prognosis of oropharyngeal cancers (OPCs) is discussed controversially.

Here, we present an analysis of about 144,969 head and neck cancer cases (ICD-10 codes: C00-C13) with a sub-cohort of 62,775 tumor cases of the oropharynx (C02, C09, C10). To this end, de-identified data from electronic health records (EHRs) of about 40 health care organizations from 30 different countries were used. Odds ratios (ORs), hazard ratios (HRs) and Kaplan-Meier analyses were used to compare outcomes between different cancer entities of neoplasms of the dorsal surface, of the tongue (C02), of tonsils (C09) and of the oropharynx (C10) of females and males with and without HPV infection. To avoid the bias from different age-distributions, the cohorts were balanced using propensity score matching.

The 5-year survival rate for HPV positive patients is somewhat better than for HPV negative patients but for age- and sex-balanced cohorts there remains no significant advantage for HPV positive patients (HR 1.126 (0.897-1.413). Looking at the different entities and HPV status for age-matched male and female patients separately, HPV is a significantly positive prognostic factor for females in all entities, whereas for male patients it is only a positive prognostic factor for malignant neoplasms of oropharynx (C10) (HR $1.077(0.602-1.926))$.

\section{Introduction}

Head and neck cancers, most of which are histologically squamous cell carcinomas consist of cancers of the oral cavity, hypopharynx, and oropharynx. Oropharyngeal carcinomas (OPC) are one of the most common subtypes of head and neck cancers [1]. While the total incidence decreases, due to the decline in traditional risk factors such as nicotine or alcohol, the incidence of HPV positive OPC has tripled in the United States between 1988 and 2004 and overhauled vaginal and cervical cancer incidence [2].

In the United States and Western Europe $70-80 \%$ of all OPCs are associated with HPV [3]. OPCs include carcinomas of the tonsils (TSCC), the base of the tongue (BTSCC), the posterior pharynx wall and the soft palate [4]. For healthy patients the prevalence of an oral HPV infection is approximately $6.1 \%$, including $1 \%$ HPV16, with a higher prevalence in men (10.1\%) than in women (3.6\%) [5].

Generally, patients are younger and healthier and have a significantly lower incidence of traditional risk factors such as smoking and alcohol abuse [6],[7].

Clearance of the virus was observed for $90 \%$ of the patients within one to two years [8]. In the remaining $10 \%$ the infections persist with a risk of malignant transformation. Since HPV is a sexually transmitted disease sexual behavior is considered as the major risk factor for HPV positive OPC. The number of oral sexual intercourse partners is the strongest associated factor. Partner of patients with HPV positive OPC do not seem to have a higher risk of a persisting HPV infection, since they are able to eliminate the virus 
[9],[10]. The fact of males being more likely to have a HPV positive OPC is probably related to the number of copies of HPV in vaginal and cervical tissue being higher than on the penis [11].

HPV Infection and Carcinogenesis

More than 200 genotypes of HPV have been identified, of which 15 are classified to have oncogenic potential [12]. HPV has a tropism for squamous epithelium, it is limited to the basal cells of the stratified epithelium and infects epithelial tissues through micro-abrasions and epithelial trauma, after sexual transmission [13].

The diagnosis of HPV is challenging as most OPCs have small primary tumor sizes. Though extensive and in many cases lymph node involvement, the diagnosis is usually made in progressed stages due to swollen lymph nodes [14].

On the one hand, according to the prevailing view in literature, HPV positive head and neck cancer is linked with a more favorable prognosis when compared to HPV negative disease [15]. On the other hand, after comparing different studies, it is noticeable that HPV positive OPC patients are younger at the point of diagnose and had less comorbidities (or regardless of comorbidities) than HPV negative OPC patients [16].

As sex has been identified as an independent parameter in the onset of HPV positive OPC, up to date no studies about the influence of sex on long-term survival rates are available, this current study contains an analysis of HPV positive OPC according to age and sex with respect to survival rates during 5-year followup.

\section{Methods}

Database and Inclusion Criteria

This work distributes a retrospective analysis of an international head and neck cancer cohort including 144,969 cases. Sub-cohorts were defined by HPV status and male or female patients. Head and neck cancer patients were identified via the ICD-10 code (C00-C13), a sub-cohort for OPC was generated using ICD-10 codes C02, 09, 10. Additionally, cohorts of HPV positive and negative patients were carefully defined based on criteria which can be found in the supplementary material. The data were gathered from electronic health records (EHRs) in a TriNetX Real World database. The real world evidence (RWE) has been provided by a global health research network with 40 healthcare organizations allocated in 30 countries, which represent a continually updated global health network of over 300 million patients.

\section{TriNetX}

The TriNetX platform assures the quality of data to be controlled by processes and procedures triggered in response to questions about the data provided. TriNetX combines longitudinal clinical data and 
analytics to help generating real-world evidence. Datasets do not leave hospitals: queries are executed in a federated manner, and only aggregated results are visible on TriNetX.

\section{Statistical Analysis}

TriNetX analytics tools were used to obtain baseline characteristics, balance cohorts with propensity score matching and analyze outcomes of interest in the final cohorts. The index event for each analysis was selected as the diagnosis of head and neck cancer (ICD 10: C00-C14) within the last five years excluding adenocarcinomas. Baseline characteristics, including demographics and diagnoses were obtained. To compare the outcomes of different cancer entities for males and females with and without HPV infection we applied hazard ratios (HR) with 95\% confidence intervals (Cls) and generated KaplanMeier curves. Propensity score matching was used to balance cohorts. Propensity scores matched cohorts 1:1 using a nearest neighbor greedy matching algorithm with a caliper of 0.25 times the standard deviation. The primary outcome was defined as death.

\section{Results}

We analyzed 144,969 cases of head and neck cancer and selected 62,775 cases of OPC (ICD-10 C02, $\mathrm{C09}, \mathrm{C} 10)$ for a detailed analysis. The consolidated standard of reporting trial (CONSORT) flow diagram, shown in Fig. 1, illustrates the data extraction process from the TriNetX Real-World database (database accessed December 7th 2020).

Overall, tumors of the tongue base had the highest frequency followed by mouth and tonsils (Table 1). Comparing male and female patients it can be noticed that all entities are represented more often in male patients. 
Table 1

Characteristics of the full cohort with frequencies of tumor entities and sex.

\begin{tabular}{|llllll|}
\hline ICD-10 & Region & Number of cases & Frequency & Male & Female \\
\cline { 5 - 6 } & & & [in percent] & \\
\hline C00 & lip & 5,221 & 4 & 67 & 33 \\
\hline C01 & tongue & 17,544 & 12 & 79 & 21 \\
\hline C02 & tongue base & 26,345 & 18 & 68 & 32 \\
\hline C03 & gum & 5,637 & 4 & 55 & 45 \\
\hline C04 & mouth floor & 8,120 & 5 & 67 & 33 \\
\hline C05 & palate & 5,763 & 4 & 59 & 41 \\
\hline C06 & mouth & 22,460 & 16 & 63 & 37 \\
\hline C09 & tonsil & 18,699 & 13 & 80 & 20 \\
\hline C10 & oropharynx & 17,731 & 12 & 77 & 23 \\
\hline C11 & nasopharynx & 8,388 & 6 & 64 & 36 \\
\hline C12 & sinus & 3,109 & 2 & 82 & 18 \\
\hline C13 & hypopharynx & 5,942 & 4 & 77 & 23 \\
\hline & All cases & 144,969 & 100 & 70 & 30 \\
\hline
\end{tabular}

In Table 1 the total number of cases sorted by different ICD-10 codes is displayed, separately broken down to male and female and relative frequency of each cancer entity within the comparison.

The sum of cases amounts 144,969 with a percentage distribution of $70 \%$ male and $30 \%$ female patients.

The prominence of malignant neoplasm of base of tongue (C02) is striking, with a frequency of $18 \%$ and a total of 26,345 patients it is the most common carcinoma in this study. Followed by mouth cancer (C06) with a frequency of $16 \%$.

In terms of distribution of male and female, it is noticeable that the percentage for each ICD-10 code of male patients is higher compared to the proportion of female.

$\mathrm{C} 12$, malignant neoplasm of pyriform sinus, has the highest proportion of male patients with $82 \%$, with a total frequency of only $2 \%$.

The largest distribution of female individuals can be seen in $\mathrm{C03}$, malignant neoplasm of the gum, in which both sexes are almost evenly distributed (male: $55 \%$, female: $45 \%$ ). 
Table 2

Survival rates in percent for oropharyngeal carcinomas, subdivided by diagnosis (ICD-10 C02, C09, C10), sex (male, female) and HPV status (HPV+/-). Hazard Ratios were calculated for HPV positive and negative cases as well as for HPV positive male and female cases (middle), Confidence intervals (Cls) are given in brackets.

\section{Oropharyngeal carcinomas}

(ICD-10 C02, C09, C10)

\begin{tabular}{|c|c|c|c|c|c|c|c|c|}
\hline \multirow{4}{*}{$\begin{array}{l}\text { Entity of } \\
\text { tumor }\end{array}$} & \multicolumn{4}{|l|}{ male } & \multicolumn{3}{|c|}{ female } & \\
\hline & \multicolumn{3}{|c|}{$\begin{array}{l}\text { Survival rate [\%] after } \\
\text { propensity score matching }\end{array}$} & \multirow{3}{*}{$\begin{array}{l}\text { \vs. } \nabla \\
\text { HPV+ } \\
\text { Hazard } \\
\text { Ratio } \\
\text { (Cl) }\end{array}$} & \multicolumn{3}{|c|}{$\begin{array}{l}\text { Survival rate [\%] after } \\
\text { propensity score matching }\end{array}$} & \multirow{3}{*}{$\begin{array}{l}\text { Entity of } \\
\text { tumor }\end{array}$} \\
\hline & \multirow[t]{2}{*}{ HPV- } & \multirow[t]{2}{*}{$\begin{array}{l}\text { Hazard } \\
\text { Ratio (Cl) }\end{array}$} & \multirow[t]{2}{*}{$\mathrm{HPV}+$} & & \multirow[t]{2}{*}{ HPV+ } & & \multirow[t]{2}{*}{ HPV- } & \\
\hline & & & & & & Ratio (Cl & & \\
\hline \multirow{2}{*}{$\begin{array}{l}\text { tongue } \\
\text { base }\end{array}$} & \multirow[t]{2}{*}{79.3} & 0.971 & \multirow[t]{2}{*}{78.8} & 0.835 & \multirow[t]{2}{*}{83.7} & 0.851 & \multirow[t]{2}{*}{81.3} & \multirow{2}{*}{$\begin{array}{l}\text { tongue } \\
\text { base }\end{array}$} \\
\hline & & $\begin{array}{l}(0.62- \\
1.521)\end{array}$ & & $\begin{array}{l}(0.457- \\
1.524)\end{array}$ & & $\begin{array}{l}(0.378- \\
1.918)\end{array}$ & & \\
\hline \multirow[t]{2}{*}{ tonsil } & \multirow[t]{2}{*}{87.8} & 0.8 & \multirow[t]{2}{*}{83.8} & 0.578 & \multirow[t]{2}{*}{90.3} & \multirow{2}{*}{$\begin{array}{l}2.157 \\
(0.86- \\
5.408)\end{array}$} & \multirow[t]{2}{*}{75.5} & \multirow[t]{2}{*}{ tonsil } \\
\hline & & $\begin{array}{l}(0.51- \\
1.257)\end{array}$ & & $\begin{array}{l}(0.262- \\
1.281)\end{array}$ & & & & \\
\hline \multirow[t]{2}{*}{ oropharynx } & \multirow[t]{2}{*}{66.3} & \multirow{2}{*}{$\begin{array}{l}1.871 \\
(1.284- \\
2.724)\end{array}$} & \multirow[t]{2}{*}{81.5} & 1.077 & \multirow[t]{2}{*}{80.6} & 2.148 & \multirow[t]{2}{*}{61.0} & \multirow[t]{2}{*}{ oropharynx } \\
\hline & & & & $\begin{array}{l}(0.602- \\
1.926)\end{array}$ & & $\begin{array}{l}(1.136- \\
4.062)\end{array}$ & & \\
\hline
\end{tabular}

The sex inequality in 5-year survival rate with and without HPV positive oropharyngeal carcinoma is illustrated in Table 2. It differentiates between male and female individuals with oropharyngeal cancers $(\mathrm{C02}, \mathrm{C} 09, \mathrm{C} 10)$ either tested positive and negative for HPV. In the center column the hazard ratio between male and female is applied.

Comparing cancers with varying localization $(\mathrm{C} 02, \mathrm{C09}, \mathrm{C} 10)$ within male patients, it can be found, that the survival rates between patients tested HPV positive and HPV negative differs. Individuals with oropharynx carcinomas (C10) tested HPV negative have a survival rate after propensity score matching of $66.3 \%$ in turn of patients tested HPV positive, who occurred to have a significantly higher survival rate of $81.5 \%$. The hazard ratio of 1.077 after age/sex matching shows that in this cancer entity HPV infection is associated with a survival advantage.

For C09, neoplasms of the tonsils, it occurs that HPV negative male patients have an $87.8 \%$ chance of surviving, which is $4 \%$ higher than male HPV positively tested C09 patients.

In the sub-cohorts of female patients, tonsil (C09) and oropharynx (C10) carcinomas in the HPV positive cohorts have a $15-20 \%$ higher survival rate in comparison to the HPV negative females, with a hazard 
ratio larger than 2.

The disparities do not only appear within one sex, differences in survival rate and hazard ratio are also noticeable between both sexes. Malignant neoplasms of tongue base (C02) and tonsils (C09) have an almost 6-7\% higher survival rate for female patients with HPV. Only in malignant neoplasms of the oropharynx male and female survival rates did hardly differ from each other.

Looking at Kaplan-Meier analysis A, which is comparing the survival rate of HPV negative (green) with HPV positive (orange) tested OPC patients, it can be seen, that HPV positive patients have a slightly higher probability of surviving within 5 years (from event occurrence to end of trial). HPV positive cohorts seem to have an advantage.

For HPV positive OPC (C02, C09, C10) Kaplan-Meier analysis B; C and D were created separately and sexmatched.

Tongue base neoplasms (C02) male (green) or female (purple) individuals display a similar trend up to 2.5 years. After this time a divergency between the survival rate of female and male can be seen. Female patients are more likely to survive a neoplasm of tongue base than HPV positive male patients are.

While the divergence for C02 firstly appears after 2.5 years, the survival rate of the sub-cohort of C09 of the two sexes departs after 114 days. Kaplan-Meier analysis $C$ exhibits quite a significant disparity, the curve of female patients shows a slow decline and keeps a steady level of 0.9 after 1211 days, whereas the male sub-cohort continuously decreases down to 0.83 .

Kaplan-Meier analysis D, neoplasms of the oropharynx (C10) depicts a similar development between the survival rate of female and male patients.

In conclusion, HPV is a better prognostic marker for female tongue base and tonsil carcinoma patients, than it is for HPV positive male patients.

\section{Discussion}

Traditional risk factors for the onset of Head and Neck Squamous Cell Carcinomas (HNSCC), which comprise of cancers of the oral cavity (OSCC) as well as Oropharyngeal cancers (OPC), are the use of nicotine and alcohol. Nevertheless, an increasing number of HNSCC can be associated with infection with the human papillomavirus (HPV). In the United States alone, the incidence of HPV positive OPC increased by about $225 \%$ between 1988 and 2004 , as is considered to be responsible for up to $90 \%$ of all new OPC cancers nationwide [17], [2]. Especially for OPC a significant correlation between HPV infection and a more favorable prognosis of the disease has been reported. Despite the increasing incidence of this entity, young and healthy patients, affected by HPV positive OPC, are still an unfamiliar cohort, seeking medical advice for cancer symptoms, delaying the diagnosis and treatment [17]. Infections with HPV are being classified as sexually transmitted diseases (STD) account for the most common STD according to WHO. However, as transmission occurs through sexual contact, most infections remain asymptomatic 
and are spontaneously cleared within the first two years, highly oncogenic subtypes of HPV are described [18]. Especially, HPV-16 is known to be responsible for most HPV-related cancer cases, making it susceptible to vaccination [19]. HPV positive OPC have significantly better prognosis than HPV negative OPC. Standardized HPV status assessment is now used for risk stratification on a routine basis. Ang et al. describe a 3-year overall survival (OS) of $82.4 \%$ in HPV positive, $57.1 \%$ in HPV negative disease respectively. In HPV positive OPC patients without a history of smoking and no lymph node involvement 3 -year OS rates of $93 \%$ seem reasonable [20]. This is also true for long-term follow-up as Posner and colleagues report of a 5 -year OS of $82 \%$ for HPV positive versus $35 \%$ for HPV negative OPC patients [21].

As an additional parameter in OS analyses of HPV positive HNSCC, several studies have identified the racial background of the patients. Not only differ the rates of HPV infections between black and white study populations, but also survival rates are supposedly better in African Americans with HPV-positive OPC [22], [23]. The influence of sex on OS in OPC has been published in a smaller study population by Fakhry et al. in 2017 [24]. HPV positive OPC in women were shown to have a survival advantage in comparison with men. Although the incidence of HPV-positive OPC is lower among women than men, the vast majority of OPC in women are HPV-positive [24]. Our data including a larger study population, shows a general higher OS in HPV positive OPC, despite the specific anatomical location. This is congruent with reports from the literature. However, in subanalysis of anatomical locations and sex, differences in OS between male and female patients could be observed. Our data shows significantly better survival rates for females with cancers of the tongue base and the tonsils compared to males with HPV positive cancers in the same regions. Although, these findings support data published by Fakhry et al. in a smaller study population, a reliable explanation is still missing. Female sex indeed seems to be an independent prognostic factor for OS in OPC. This has been subject to research in other tumor entities, leaving male subpopulations with worse survival rates than female ones [25]. One explanation could be that women have less tobacco and alcohol exposure than men, still being a cofounder even in HPV positive OPC. For non-squamous cell lung cancers, improved survival rates in female patients are explained by distinct phenotypes of disease by sex rather than smoking as a risk factor [26]. Moreover, comorbidities and general death rates could also add up to this equation. This current study underlines the role of sexes as an independent risk factor in HPV associated OPC providing a large sample size. Nevertheless, the retrospective study design and the large cohort cannot reveal differences in tobacco and alcohol abuse and comorbidities. HPV testing is emphasized by the results of this study, identifying patients at risk for disease recurrence. Moreover, the biological sex should be established as an independent risk factor.

\section{Conclusion}

Sex disparities, differences between tumor entities and HPV diagnoses result in significantly varying survival rates and reveal the necessity of customized, patient specific prognoses and therapies. Causes for these disparities demand further investigation and warrant a re-evaluation of therapy strategies, in order to improve clinical practical guidelines and enable optimal treatment for patients with oropharyngeal cancer. 


\section{Declarations}

Ethics approval and consent to participate

Not applicable

Consent for publication

Not applicable

Availability of data and materials

The datasets used are available in the supplementary material..

\section{Funding}

This work was funded by the German Research Foundation (DFG: PR 1562/1-1).

Competing interests

The authors declare that they have no competing interests.

Authors' contributions

SHP analyzed and interpreted data, wrote the first version of the manuscript, designed Figures

SN analyzed and interpreted data.

SP conceived the study, performed the analysis, wrote the manuscript.

$\mathrm{MH}$ analyzed and interpreted data.

BBB analyzed and interpreted data.

SK analyzed and interpreted data, wrote the manuscript.

All authors read and approved the final version of the manuscript.

Acknowledgements

Not applicable.

\section{References}

1. Tang, K.D.; Baeten, K.; Kenny, L.; Frazer, I.H.; Scheper, G.; Punyadeera, C. Unlocking the Potential of Saliva-Based Test to Detect HPV-16-Driven Oropharyngeal Cancer. Cancers (Basel) 2019, 11, doi:10.3390/cancers 11040473 . 
2. Chaturvedi, A.K.; Engels, E.A.; Pfeiffer, R.M.; Hernandez, B.Y.; Xiao, W.; Kim, E.; Jiang, B.; Goodman, M.T.; Sibug-Saber, M.; Cozen, W., et al. Human papillomavirus and rising oropharyngeal cancer incidence in the United States. J Clin Oncol 2011, 29, 4294-4301, doi:10.1200/JC0.2011.36.4596.

3. O'Sullivan, B.; Huang, S.H.; Su, J.; Garden, A.S.; Sturgis, E.M.; Dahlstrom, K.; Lee, N.; Riaz, N.; Pei, X.; Koyfman, S.A., et al. Development and validation of a staging system for HPV-related oropharyngeal cancer by the International Collaboration on Oropharyngeal cancer Network for Staging (ICON-S): a multicentre cohort study. Lancet Oncol 2016, 17, 440-451, doi:10.1016/S1470-2045(15)00560-4.

4. Nasman, A.; Du, J.; Dalianis, T. A global epidemic increase of an HPV-induced tonsil and tongue base cancer - potential benefit from a pan-gender use of HPV vaccine. J Intern Med 2020, 287, 134-152, doi:10.1111/joim.13010.

5. Gillison, M.L.; Broutian, T.; Pickard, R.K.; Tong, Z.Y.; Xiao, W.; Kahle, L.; Graubard, B.I.; Chaturvedi, A.K. Prevalence of oral HPV infection in the United States, 2009-2010. JAMA 2012, 307, 693-703, doi:10.1001/jama.2012.101.

6. Deschler, D.G.; Richmon, J.D.; Khariwala, S.S.; Ferris, R.L.; Wang, M.B. The "new" head and neck cancer patient-young, nonsmoker, nondrinker, and HPV positive: evaluation. Otolaryngol Head Neck Surg 2014, 151, 375-380, doi:10.1177/0194599814538605.

7. Pytynia, K.B.; Dahlstrom, K.R.; Sturgis, E.M. Epidemiology of HPV-associated oropharyngeal cancer. Oral Oncol 2014, 50, 380-386, doi:10.1016/j.oraloncology.2013.12.019.

8. Ljubojevic, S.; Skerlev, M. HPV-associated diseases. Clin Dermato/ 2014, 32, 227-234, doi:10.1016/j.clindermatol.2013.08.007.

9. D'Souza, G.; Gross, N.D.; Pai, S.I.; Haddad, R.; Anderson, K.S.; Rajan, S.; Gerber, J.; Gillison, M.L.; Posner, M.R. Oral human papillomavirus (HPV) infection in HPV-positive patients with oropharyngeal cancer and their partners. J Clin Oncol 2014, 32, 2408-2415, doi:10.1200/JC0.2014.55.1341.

10. Cossellu, G.; Fedele, L.; Badaoui, B.; Angiero, F.; Farronato, G.; Monti, E.; Liverani, C.A.; Gorni, C.; Botti, S. Prevalence and concordance of oral and genital HPV in women positive for cervical HPV infection and in their sexual stable partners: An Italian screening study. PLoS One 2018, 13, e0205574, doi:10.1371/journal.pone.0205574.

11. Taylor, S.; Bunge, E.; Bakker, M.; Castellsague, X. The incidence, clearance and persistence of noncervical human papillomavirus infections: a systematic review of the literature. BMC Infect Dis 2016, 16, 293, doi:10.1186/s12879-016-1633-9.

12. Dube Mandishora, R.S.; Gjotterud, K.S.; Lagstrom, S.; Stray-Pedersen, B.; Duri, K.; Chin'ombe, N.; Nygard, M.; Christiansen, I.K.; Ambur, O.H.; Chirenje, M.Z., et al. Intra-host sequence variability in human papillomavirus. Papillomavirus Res 2018, 5, 180-191, doi:10.1016/j.pvr.2018.04.006.

13. Syrjanen, S. Oral manifestations of human papillomavirus infections. Eur J Oral Sci 2018, 126 Suppl 1, 49-66, doi:10.1111/eos.12538.

14. Woods, R., Sr.; O'Regan, E.M.; Kennedy, S.; Martin, C.; O'Leary, J.J.; Timon, C. Role of human papillomavirus in oropharyngeal squamous cell carcinoma: A review. World J Clin Cases 2014, 2, 172-193, doi:10.12998/wjcc.v2.i6.172. 
15. Fakhry, C.; Westra, W.H.; Li, S.; Cmelak, A.; Ridge, J.A.; Pinto, H.; Forastiere, A.; Gillison, M.L. Improved survival of patients with human papillomavirus-positive head and neck squamous cell carcinoma in a prospective clinical trial. J Natl Cancer Inst 2008, 100, 261-269, doi:10.1093/jnci/djn011.

16. Gillison, M.L.; D'Souza, G.; Westra, W.; Sugar, E.; Xiao, W.; Begum, S.; Viscidi, R. Distinct risk factor profiles for human papillomavirus type 16-positive and human papillomavirus type 16-negative head and neck cancers. J Natl Cancer Inst 2008, 100, 407-420, doi:10.1093/jnci/djn025.

17. You, E.L.; Henry, M.; Zeitouni, A.G. Human papillomavirus-associated oropharyngeal cancer: review of current evidence and management. Curr Oncol 2019, 26, 119-123, doi:10.3747/co.26.4819.

18. Aimagambetova, G.; Azizan, A. Epidemiology of HPV Infection and HPV-Related Cancers in Kazakhstan: a Review. Asian Pac J Cancer Prev 2018, 19, 1175-1180, doi:10.22034/APJCP.2018.19.5.1175.

19. Bann, D.V.; Deschler, D.G.; Goyal, N. Novel Immunotherapeutic Approaches for Head and Neck Squamous Cell Carcinoma. Cancers (Basel) 2016, 8, doi:10.3390/cancers8100087.

20. Ang, K.K.; Harris, J.; Wheeler, R.; Weber, R.; Rosenthal, D.I.; Nguyen-Tan, P.F.; Westra, W.H.; Chung, C.H.; Jordan, R.C.; Lu, C., et al. Human papillomavirus and survival of patients with oropharyngeal cancer. N Engl J Med 2010, 363, 24-35, doi:10.1056/NEJMoa0912217.

21. Posner, M.R.; Lorch, J.H.; Goloubeva, O.; Tan, M.; Schumaker, L.M.; Sarlis, N.J.; Haddad, R.I.; Cullen, K.J. Survival and human papillomavirus in oropharynx cancer in TAX 324: a subset analysis from an international phase III trial. Ann Oncol 2011, 22, 1071-1077, doi:10.1093/annonc/mdr006.

22. Worsham, M.J.; Stephen, J.K.; Chen, K.M.; Mahan, M.; Schweitzer, V.; Havard, S.; Divine, G. Improved survival with HPV among African Americans with oropharyngeal cancer. Clin Cancer Res 2013, 19, 2486-2492, doi:10.1158/1078-0432.CCR-12-3003.

23. Settle, K.; Posner, M.R.; Schumaker, L.M.; Tan, M.; Suntharalingam, M.; Goloubeva, O.; Strome, S.E.; Haddad, R.I.; Patel, S.S.; Cambell, E.V., 3rd, et al. Racial survival disparity in head and neck cancer results from low prevalence of human papillomavirus infection in black oropharyngeal cancer patients. Cancer Prev Res (Phila) 2009, 2, 776-781, doi:10.1158/1940-6207.CAPR-09-0149.

24. Fakhry, C.; Westra, W.H.; Wang, S.J.; van Zante, A.; Zhang, Y.; Rettig, E.; Yin, L.X.; Ryan, W.R.; Ha, P.K.; Wentz, A., et al. The prognostic role of sex, race, and human papillomavirus in oropharyngeal and nonoropharyngeal head and neck squamous cell cancer. Cancer 2017, 123, 1566-1575, doi:10.1002/cncr.30353.

25. Cook, M.B.; McGlynn, K.A.; Devesa, S.S.; Freedman, N.D.; Anderson, W.F. Sex disparities in cancer mortality and survival. Cancer Epidemiol Biomarkers Prev 2011, 20, 1629-1637, doi:10.1158/10559965.EPI-11-0246.

26. Wakelee, H.A.; Wang, W.; Schiller, J.H.; Langer, C.J.; Sandler, A.B.; Belani, C.P.; Johnson, D.H.; Eastern Cooperative Oncology, G. Survival differences by sex for patients with advanced non-small cell lung cancer on Eastern Cooperative Oncology Group trial 1594. J Thorac Oncol 2006, 1, 441-446.

27. Tang, K. D., K. Baeten, L. Kenny, I. H. Frazer, G. Scheper, and C. Punyadeera. "Unlocking the Potential of Saliva-Based Test to Detect Hpv-16-Driven Oropharyngeal Cancer." Cancers (Basel) 11, no. 4 
(2019).

28. Chaturvedi, A. K., E. A. Engels, R. M. Pfeiffer, B. Y. Hernandez, W. Xiao, E. Kim, B. Jiang, M. T. Goodman, M. Sibug-Saber, W. Cozen, L. Liu, C. F. Lynch, N. Wentzensen, R. C. Jordan, S. Altekruse, W. F. Anderson, P. S. Rosenberg, and M. L. Gillison. "Human Papillomavirus and Rising Oropharyngeal Cancer Incidence in the United States." J Clin Oncol 29, no. 32 (2011): 4294-301.

29. O'Sullivan, B., S. H. Huang, J. Su, A. S. Garden, E. M. Sturgis, K. Dahlstrom, N. Lee, N. Riaz, X. Pei, S. A. Koyfman, D. Adelstein, B. B. Burkey, J. Friborg, C. A. Kristensen, A. B. Gothelf, F. Hoebers, B. Kremer, E. J. Speel, D. W. Bowles, D. Raben, S. D. Karam, E. Yu, and W. Xu. "Development and Validation of a Staging System for Hpv-Related Oropharyngeal Cancer by the International Collaboration on Oropharyngeal Cancer Network for Staging (Icon-S): A Multicentre Cohort Study." Lancet Oncol 17, no. 4 (2016): 440 - 51.

30. Nasman, A., J. Du, and T. Dalianis. "A Global Epidemic Increase of an Hpv-Induced Tonsil and Tongue Base Cancer - Potential Benefit from a Pan-Gender Use of Hpv Vaccine." J Intern Med 287, no. 2 (2020): 134-52.

31. Gillison, M. L., T. Broutian, R. K. Pickard, Z. Y. Tong, W. Xiao, L. Kahle, B. I. Graubard, and A. K. Chaturvedi. "Prevalence of Oral Hpv Infection in the United States, 2009-2010." JAMA 307, no. 7 (2012): 693-703.

32. Deschler, D. G., J. D. Richmon, S. S. Khariwala, R. L. Ferris, and M. B. Wang. "The "New" Head and Neck Cancer Patient-Young, Nonsmoker, Nondrinker, and Hpv Positive: Evaluation." Otolaryngol Head Neck Surg 151, no. 3 (2014): 375-80.

33. Pytynia, K. B., K. R. Dahlstrom, and E. M. Sturgis. "Epidemiology of Hpv-Associated Oropharyngeal Cancer." Oral Oncol 50, no. 5 (2014): 380-6.

34. Ljubojevic, S., and M. Skerlev. "Hpv-Associated Diseases." Clin Dermato/32, no. 2 (2014): 227-34.

35. D'Souza, G., N. D. Gross, S. I. Pai, R. Haddad, K. S. Anderson, S. Rajan, J. Gerber, M. L. Gillison, and M. R. Posner. "Oral Human Papillomavirus (Hpv) Infection in Hpv-Positive Patients with Oropharyngeal Cancer and Their Partners." J Clin Oncol32, no. 23 (2014): 2408-15.

36. Cossellu, G., L. Fedele, B. Badaoui, F. Angiero, G. Farronato, E. Monti, C. A. Liverani, C. Gorni, and S. Botti. "Prevalence and Concordance of Oral and Genital Hpv in Women Positive for Cervical Hpv Infection and in Their Sexual Stable Partners: An Italian Screening Study." PLoS One 13, no. 10 (2018): e0205574.

37. Taylor, S., E. Bunge, M. Bakker, and X. Castellsague. "The Incidence, Clearance and Persistence of Non-Cervical Human Papillomavirus Infections: A Systematic Review of the Literature." BMC Infect Dis 16 (2016): 293.

38. Dube Mandishora, R. S., K. S. Gjotterud, S. Lagstrom, B. Stray-Pedersen, K. Duri, N. Chin'ombe, M. Nygard, I. K. Christiansen, O. H. Ambur, M. Z. Chirenje, and T. B. Rounge. "Intra-Host Sequence Variability in Human Papillomavirus." Papillomavirus Res 5 (2018): 180-91.

39. Syrjanen, S. "Oral Manifestations of Human Papillomavirus Infections." Eur J Oral Sci 126 Suppl 1 (2018): 49-66. 
40. Woods, R., Sr., E. M. O'Regan, S. Kennedy, C. Martin, J. J. O'Leary, and C. Timon. "Role of Human Papillomavirus in Oropharyngeal Squamous Cell Carcinoma: A Review." World J Clin Cases 2, no. 6 (2014): 172-93.

41. Fakhry, C., W. H. Westra, S. Li, A. Cmelak, J. A. Ridge, H. Pinto, A. Forastiere, and M. L. Gillison. "Improved Survival of Patients with Human Papillomavirus-Positive Head and Neck Squamous Cell Carcinoma in a Prospective Clinical Trial." J Natl Cancer Inst 100, no. 4 (2008): 261-9.

42. Gillison, M. L., G. D'Souza, W. Westra, E. Sugar, W. Xiao, S. Begum, and R. Viscidi. "Distinct Risk Factor Profiles for Human Papillomavirus Type 16-Positive and Human Papillomavirus Type 16-Negative Head and Neck Cancers." J Natl Cancer Inst 100, no. 6 (2008): 407-20.

43. You, E. L., M. Henry, and A. G. Zeitouni. "Human Papillomavirus-Associated Oropharyngeal Cancer: Review of Current Evidence and Management." Curr Oncol 26, no. 2 (2019): 119-23.

44. Aimagambetova, G., and A. Azizan. "Epidemiology of Hpv Infection and Hpv-Related Cancers in Kazakhstan: A Review." Asian Pac J Cancer Prev 19, no. 5 (2018): 1175-80.

45. Bann, D. V., D. G. Deschler, and N. Goyal. "Novel Immunotherapeutic Approaches for Head and Neck Squamous Cell Carcinoma." Cancers (Basel) 8, no. 10 (2016).

46. Ang, K. K., J. Harris, R. Wheeler, R. Weber, D. I. Rosenthal, P. F. Nguyen-Tan, W. H. Westra, C. H. Chung, R. C. Jordan, C. Lu, H. Kim, R. Axelrod, C. C. Silverman, K. P. Redmond, and M. L. Gillison. "Human Papillomavirus and Survival of Patients with Oropharyngeal Cancer." N Engl J Med 363, no. 1 (2010): 24-35.

47. Posner, M. R., J. H. Lorch, O. Goloubeva, M. Tan, L. M. Schumaker, N. J. Sarlis, R. I. Haddad, and K. J. Cullen. "Survival and Human Papillomavirus in Oropharynx Cancer in Tax 324: A Subset Analysis from an International Phase lii Trial." Ann Oncol 22, no. 5 (2011): 1071-77.

48. Worsham, M. J., J. K. Stephen, K. M. Chen, M. Mahan, V. Schweitzer, S. Havard, and G. Divine. "Improved Survival with Hpv among African Americans with Oropharyngeal Cancer." Clin Cancer Res 19, no. 9 (2013): 2486-92.

49. Settle, K., M. R. Posner, L. M. Schumaker, M. Tan, M. Suntharalingam, O. Goloubeva, S. E. Strome, R. I. Haddad, S. S. Patel, E. V. Cambell, 3rd, N. Sarlis, J. Lorch, and K. J. Cullen. "Racial Survival Disparity in Head and Neck Cancer Results from Low Prevalence of Human Papillomavirus Infection in Black Oropharyngeal Cancer Patients." Cancer Prev Res (Phila) 2, no. 9 (2009): 776-81.

50. Fakhry, C., W. H. Westra, S. J. Wang, A. van Zante, Y. Zhang, E. Rettig, L. X. Yin, W. R. Ryan, P. K. Ha, A. Wentz, W. Koch, J. D. Richmon, D. W. Eisele, and G. D'Souza. "The Prognostic Role of Sex, Race, and Human Papillomavirus in Oropharyngeal and Nonoropharyngeal Head and Neck Squamous Cell Cancer." Cancer 123, no. 9 (2017): 1566-75.

51. Cook, M. B., K. A. McGlynn, S. S. Devesa, N. D. Freedman, and W. F. Anderson. "Sex Disparities in Cancer Mortality and Survival." Cancer Epidemiol Biomarkers Prev 20, no. 8 (2011): 1629-37.

52. Wakelee, H. A., W. Wang, J. H. Schiller, C. J. Langer, A. B. Sandler, C. P. Belani, D. H. Johnson, and Group Eastern Cooperative Oncology. "Survival Differences by Sex for Patients with Advanced Non- 
Small Cell Lung Cancer on Eastern Cooperative Oncology Group Trial 1594." J Thorac Oncol 1, no. 5 (2006): 441-6.

\section{Figures}

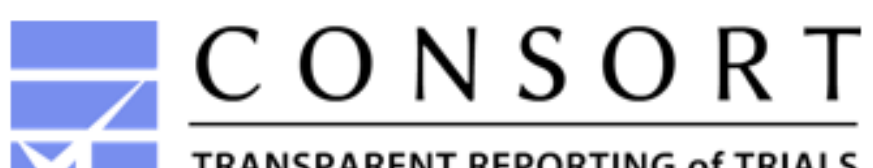

CONSORT 2010 Flow Diagram

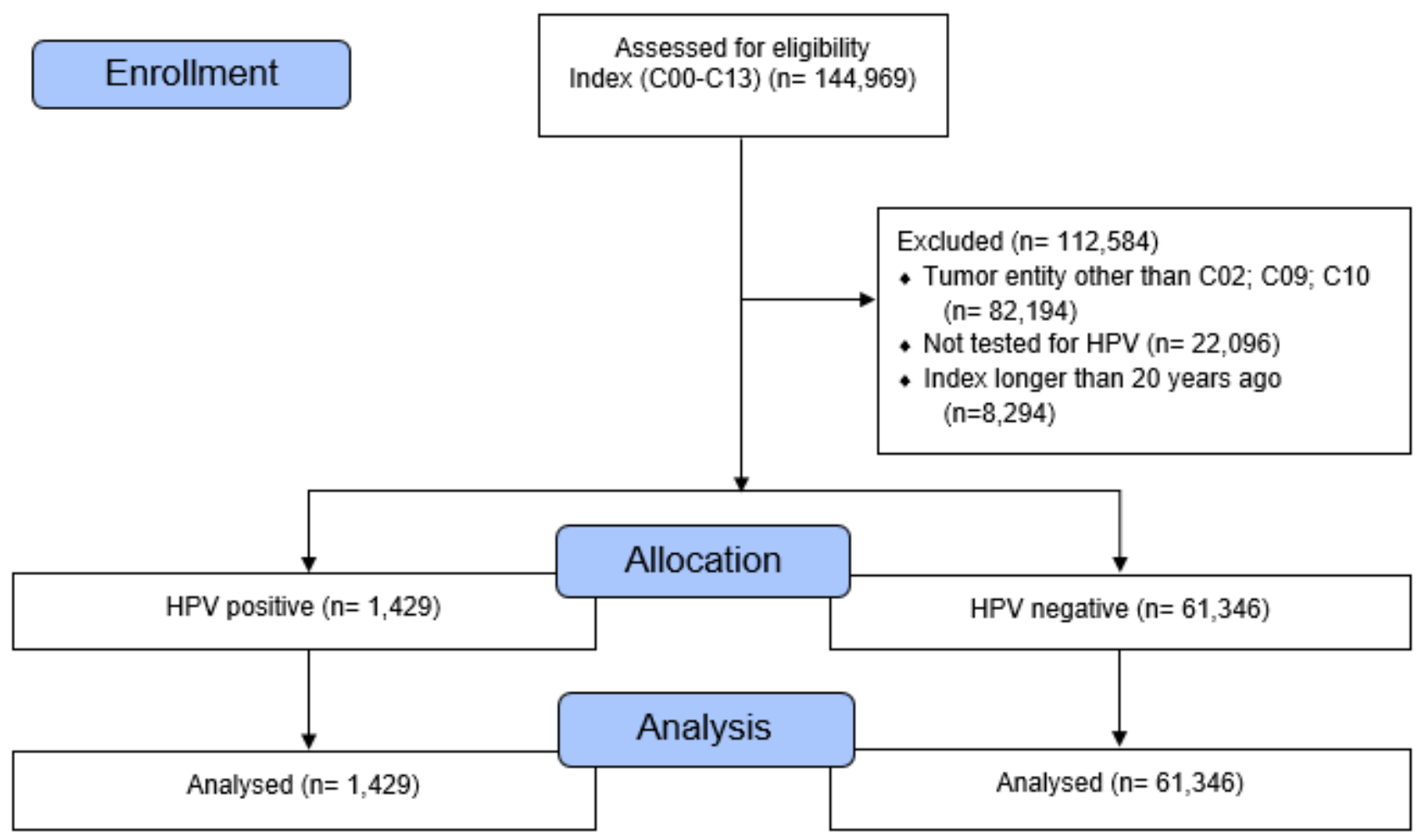

Figure 1

CONSORT flow diagram; major stages are indicated in the blue boxes. 


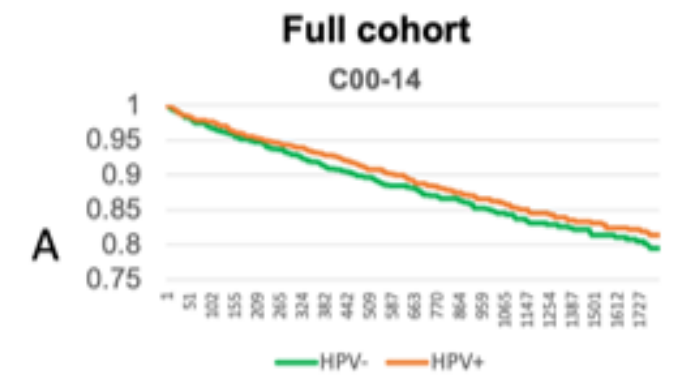

\section{Gender-matched sub-cohorts}
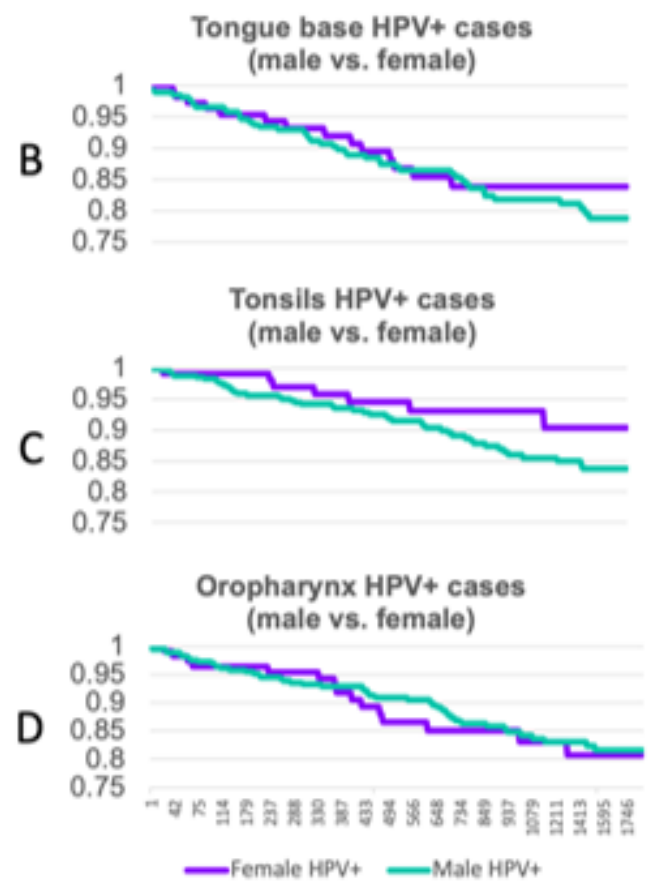

\section{Figure 2}

A: Kaplan-Meier analysis comparing the full cohort of OPC patients tested HPV positive and HPV negative B-D: Kaplan-Meier analysis of sex-matched sub-cohorts of tongue base, tonsils, oropharynx carcinoma patients with HPV comparing male (green) and female (purple) individuals

\section{Supplementary Files}

This is a list of supplementary files associated with this preprint. Click to download.

- AdditionalFiles.zip 